\title{
Successful Treatment of Refractory Melasma Using Invasive Micro-Pulsed Electric Signal Device
}

\author{
Moon Choi ${ }^{1}$ \\ Seohee Choi $^{1}$ \\ Jin-Soo Kang ${ }^{2}$ \\ Sung Bin $\mathrm{Cho}^{2,3}$
}

\footnotetext{
${ }^{1}$ Skin Life Clinic, Vancouver, Canada

${ }^{2}$ Kangskin Dermatology Clinic, Seoul, Korea

${ }^{3}$ Department of Dermatology and Cutaneous Biology Research Institute, Yonsei University College of Medicine, Seoul, Korea
}

\section{Correspondence}

Sung Bin Cho

Department of Dermatology and Cutaneous Biology Research Institute, Yonsei University College of Medicine, 50 Yonsei-ro, Seodaemoongu, Seoul 120-752, Korea

Tel: +82-2-2228-2080

Fax: +82-2-393-9157

E-mail: drsbchođggmail.com

(C) Korean Society for Laser Medicine and Surgery

(@) This is an open access article distributed under the terms of the Creative Commons Attribution NonCommercial License (http://creativecommons.org/ licenses/by-nc/4.0) which permits unrestricted noncommercial use, distribution, and reproduction in any medium, provided the original work is properly cited.

\begin{abstract}
Treatment of facial melasma refractory to low-fluence Q-switched $\mathrm{Nd}$ :YAG laser (LFQSNY) and topical lightening agents (TLA) is a challenge. The objective of this study was to investigate the safety and efficacy of an additional invasive micro-pulsed electric signal device (IMPES) for treatment of melasma refractory to LFQSNY/TLA. Five female patients (Fitzpatrick skin type III-IV) with refractory facial melasma were treated using IMPES added to their baseline of LFQSNY/ TLA treatment. Four to seven treatments were administered at 1-week intervals. The power levels ranged from 3 to 5 , depth $1.2 \mathrm{~mm}$ to $1.7 \mathrm{~mm}$, and single pass. Photographs were taken at the beginning and 1 week after the last treatment. At the last treatment, assessments showed greater than 50\% clinical improvement in melasma in all five patients. Follow-up interviews were conducted at the 8th week. No recurrence was reported during the follow-up at 8 weeks. No significant adverse effects were noted. Addition of IMPES to LFQSNY/TLA is a safe and effective treatment for refractory melasma.
\end{abstract}

\section{Key words}

Invasive micro-pulsed electric signal device; Melasma; Nd:YAG; Topical bleaching agent 


\section{INTRODUCTION}

Melasma is a common disorder of hyperpigmentation more common in women with Fitzpatrick skin phototypes III or higher. It typically appears in sun-exposed areas as a light to dark brown, irregular hypermelanotic macules and confluent patches. Histologically melasma lesions show a higher degree of ultraviolet induced damage such as solar elastosis and damaged basal membrane as well as increased vascularity. ${ }^{1-4}$ Although many treatment options are available including topical depigmenting agents, coherent and non-coherent photothermolysis, chemical peels, and oral agents, the treatment of melasma remains challenging. ${ }^{5}$

Since 2008, low-fluence Q-switched Nd:YAG laser (LFQSNY) and topical lightening agents (TLA) has become one of popular treatments. ${ }^{6}$ LFQSNY, also known as laser toning is believed to interfere with melanosome transfer and damage stage IV melanosome by subcellularselective photothermolysis. ${ }^{7}$ Although studies confirm substantial and long term therapeutic benefit of this treatment method, ${ }^{8}$ there are melasma that is resistant to LFQSNY. Here, we report five cases where melasma resistant to LFQSNY/TLA responded favorably to a modified LFQSNY/TLA with the addition to invasive micropulsed electric signed device (IMPES).

\section{CASE REPORT}

Five patients whose melasma were not responding to a standard LFQSNY/TLA were treated with an addition of IMPES (Sylfirm, SLR Inc., CA, USA) to their existing LFQSNY/TLA treatment regime (Table 1). At the time of study enrollment, all five patients had already received more than six sessions of LFQSNY combined with daily TLA use. However, patients' melasma stopped improving or failed to improve at least over 3 sessions ( 3 weeks) or longer period of time, based on both physician global assessment and patient self-assessment. All patients were female with Fitzpatrick skin types III-IV and aged between 42 and 53 years (mean: 48 years). Informed consent was obtained and the study protocol was in accordance with the guidelines of the 1975 Declaration of Helsinki. Patients received five to seven weekly sessions of LFQSNY/TLA/IMPES combination.

The face was cleansed with gentle cleanser. A topical eutectic mixture of 2.5\% lidocaine and 2.5\% prilocaine (EMLA; AstraZeneca Canada Inc., Ontario, Canada) was applied to lesional areas under occlusion for 30 minutes. Immediately upon removal of EMLA, LFQSNY (Helios II, LaserOptek Co. Ltd., Kyunggi, South Koreal was used to paint the entire face at the following settings: fluence $1.89 \mathrm{~J} / \mathrm{cm}^{2}$, a spot size of $8 \mathrm{~mm}$, a repetition rate of $10 \mathrm{~Hz}$, $<10 \%$ overlap, and the end-point of mild erythema. IMPES treatment was immediately followed: a power levels ranged from 3 to 5 , penetration depth $1.2 \mathrm{~mm}$ to $1.7 \mathrm{~mm}$, single pass, and $<10 \%$ overlap. All patients were asked to continue with their existing topical medications and sun protection routine.

Digital photographs were taken at the study enrollment and 1 week after the last treatment session. Clinical improvement scores were determined by the treating physician based on pre and post treatment photographs using tertile grading scale: 1-33\%, minimal clearance; 34$66 \%$, moderate clearance; $67-100 \%$, marked clearance. Based on pre- and post-treatment photographs, moderate to marked improvement was observed in all five patients (Table 2, Fig. 1-3). In addition, a reduction of pore sizes and an increase of skin's textural homogeneity were observed. Patients reported mild to moderate pain at the time of IMPES treatment. Mild erythema and edema was noted post-treatment, which resolved within several hours. No adverse events including a formation of scabs were reported.

\section{DISCUSSION}

Here, we report five cases of resistant melasma that

Table 1. Patients' demographics

\begin{tabular}{ccllrl}
\hline Patient & Skin type & \multicolumn{1}{c}{ Location } & Baseline treatment (BT) & No. of BT* & \multicolumn{1}{c}{ Remark } \\
\hline 1 & IV & Temple, cheek, eyelid, perioral, and chin & LFOSNY, TR, and HO & 12 & Diabetes, HTN (controlled with medications) \\
2 & III & Cheek and forehead & LFOSNY, TR, HQ, and TC & 8 & \\
3 & III & Cheek & LFOSNY, TR, and KA & 6 & Allergic to HO \\
4 & III & Cheek & LFOSNY and AA & 7 & Unable to tolerate TR, HQ, and KA. \\
5 & IV & Cheek & LFOSNY and HO & 7 & Unable to tolerate TR \\
\hline
\end{tabular}

TR, 0.01-0.025\% tretinoin; HQ, 4\% hydroquione; KA, 3\% Kojic acid; AA, 15\% ascorbic acid; TC, 0.01\% triamcinolone; HTN, hypertension. * Number of baseline treatment patient received prior to study enrollment. 
were successfully treated with an addition of IMPES to patients' existing treatment regime. To our knowledge, the present study is the first reported cases of melasma treated successfully with an IMPES. IMPES's system

Table 2. Summary of results

\begin{tabular}{cccc}
\hline Patient & $\begin{array}{c}\text { Treatment } \\
\text { sessions }\end{array}$ & $\begin{array}{c}\text { Clinical improvement } \\
\text { score }\end{array}$ & Adverse event \\
\hline 1 & 7 & $67-100$ & None \\
2 & 7 & $67-100$ & None \\
3 & 5 & $67-100$ & None \\
4 & 5 & $34-66$ & None \\
5 & 7 & $67-100$ & None \\
\hline
\end{tabular}
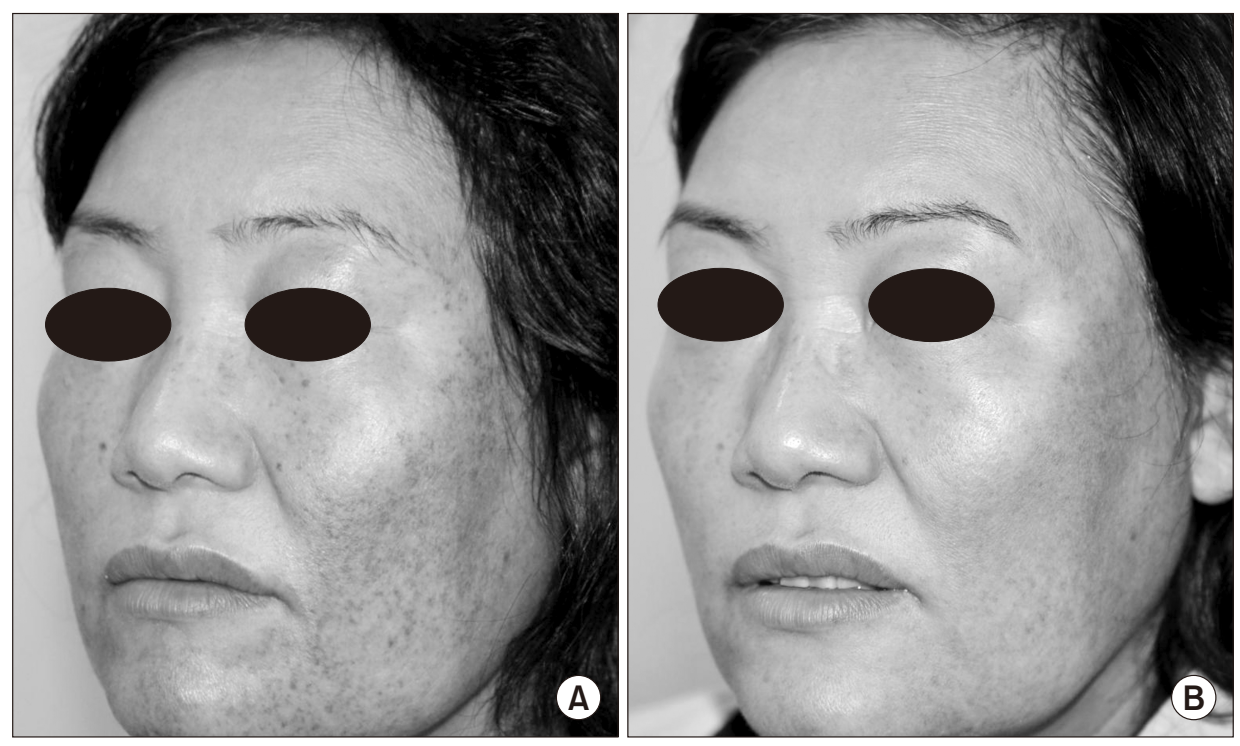

Fig. 1. (A) Baseline and (B) Posttreatment (taken 1 week after the last treatment) photographs of patient 1 show lightening of melasma. Note that patient received an additional procedure to remove facial seborrheic keratosis prior to receiving IMPES.
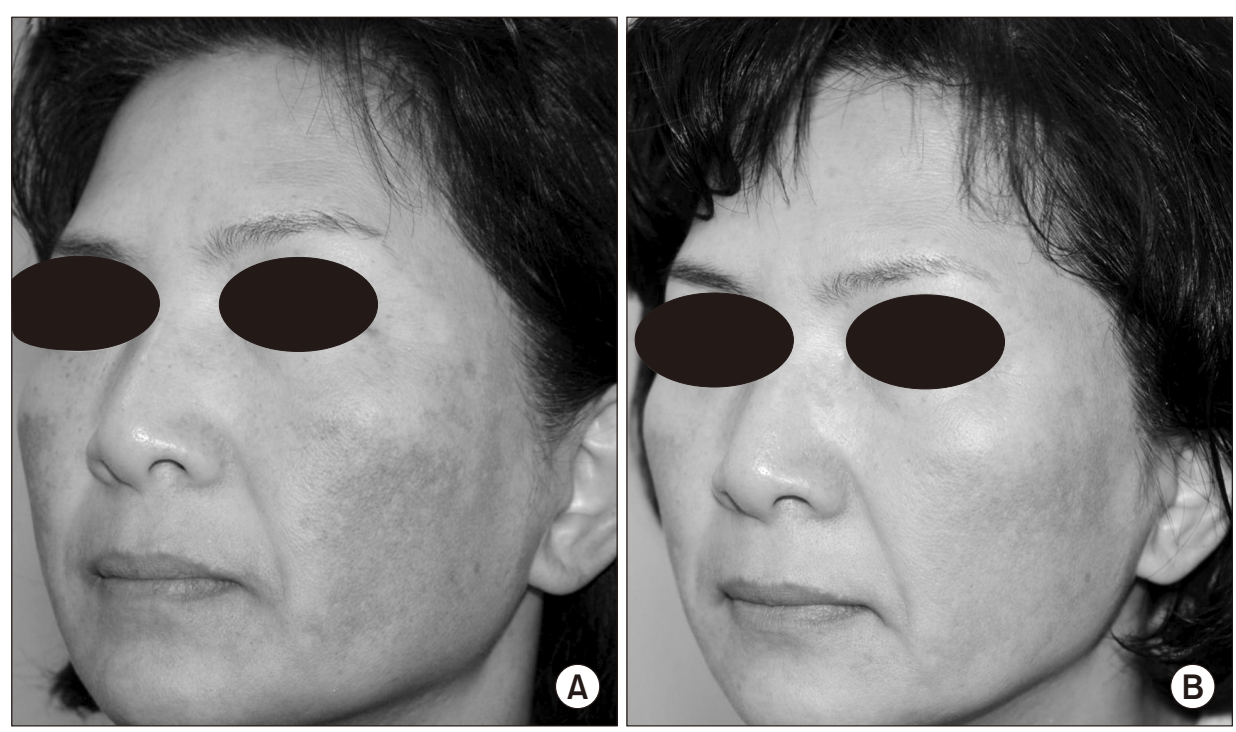

Fig. 2. (A) Baseline and (B) Posttreatment (taken 1 week after the last treatment) photographs of patient 2 show lightening of melasma, textural improvement. 

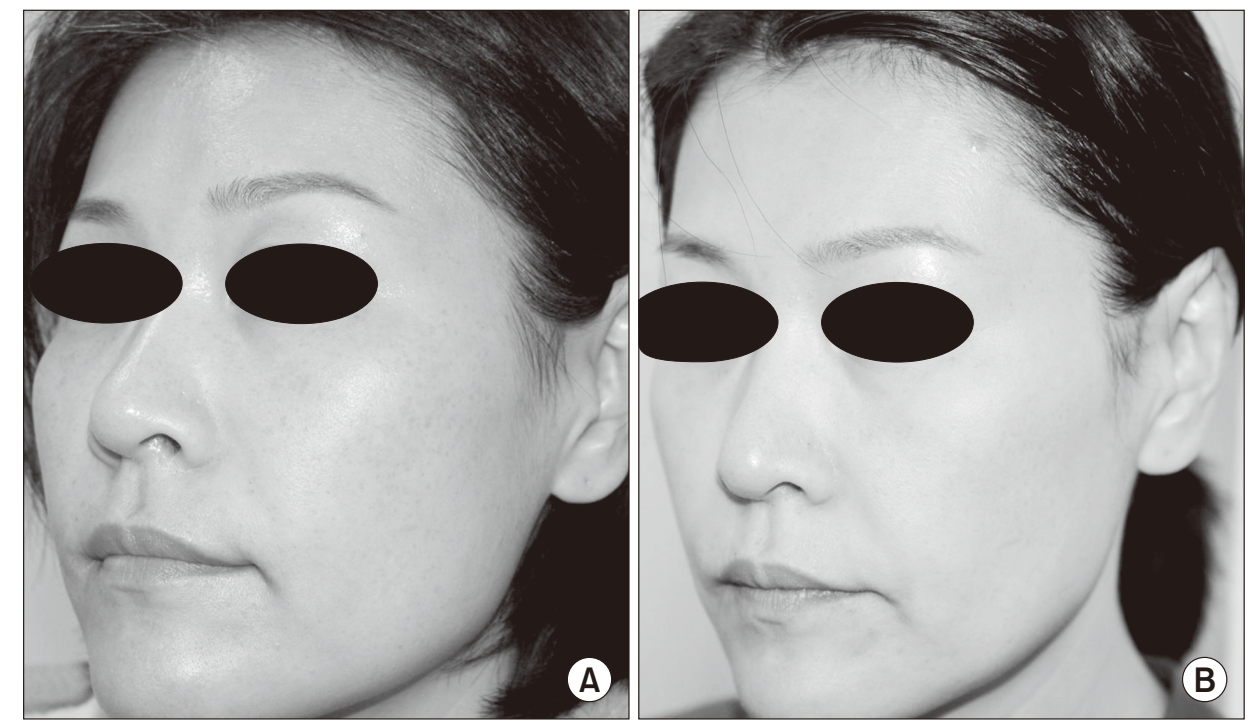

Fig. 3. (A) Baseline and (B) Posttreatment (taken 1 week after the last treatment) photographs of patient 3 show lightening of melasma.

may lead to stimulation of melanocytes with subsequent post-inflammatory hyperpigmentation. In addition, a significant fractional photothermolysis of epidermaldermal junction can worsen melanin incontinence by weakening basal membrane. ${ }^{15}$ A comparative study failed to show additional benefit of adding fractional photothermolysis to LFQSNY treatment for the purpose of treating melasma. ${ }^{16}$

The exact mechanism by which IMPES improved melasma is not investigated in our study. In many fractional laser studies have considered transepidermal elimination of melanin as the primary mode of action. However, skin treated with IMPES did not show any obvious micro-crusting or increased epidermal shedding. An experiment of non-insulated penetrating electrode placed in soft tissue of relatively uniform electrical impedance showed that under certain settings, thermal coagulation can be limited to the tip of the electrode and made to expand to the entire length of the needle by increasing energy. ${ }^{17}$ It is known that radio frequency current from the needle electrodes placed in epidermis and dermis preferentially travels through tissues of higher electrical conductivity. Epidermis is known to exhibit greater electrical resistance. ${ }^{18}$ The higher water content and presence of vasculature confer higher conductivity in the dermis. Therefore under certain conditions, noninsulated penetrating needle electrodes may deliver radio frequency energy almost exclusively to dermis without significant damage to overlying structures such as epidermis and basal membrane. A study of insulated needle electrodes radio frequency device shows that an increased number of fibroblasts including alteration of micro-environment were found after deep dermal heating. ${ }^{19}$

We speculate that the IMPES may work through different modes of action including enhancing permeability of TLA, increasing degradation of dermal vasculature, and reversing a number of known histological changes associated with melasma. The therapeutic effects of TLA are known to be limited by their poor transdermal penetration. A study with nonenergized multiple micro-needles demonstrated that methylene blue dye used in the experiment penetrated both epidermis and dermis through vertical epidermodermal fissure created by microneedle treatment. ${ }^{20}$ In addition, the delivery of anti-melanogenic agents via microneedling is reported to be an effective treatment method for melasma. ${ }^{21}$ Similarly, micro-channels created by IMPES' needle electrodes may lead to enhanced transdermal drug delivery, thus improving their antimelanogenesis effects of the TLA used by the patients. A number of studies showed increased vascularization, melanin incontinence, and solar elastosis in lesional skin of melasma. Although the role of the vascularization in melasma is still yet to be understood, studies demonstrated that therapies targeting the vascularization can lead to improvement of melasma. ${ }^{22,23}$ The higher electric conductivity of vasculature may preferentially induce dermal vasculature to be coagulated before coagulating epidermis and dermis by IMPES. Fibroblasts in the dermis are able to secrete pro-melanogenesis paracrine factors such as IL-1 $\alpha, E T-1$, ET-3, SCF, growth related oncogene- $\alpha$, c-Kit, GM-CSF, hepatocyte growth factor, and prostaglandin-2 depending on the conditions 
of their micro-environment. Previous studies have shown that bipolar fractional radio frequency treatment can reverse solar elastosis by inducing neoelastogenesis and neocollagenesis. ${ }^{24}$ Alteration of micro-environment caused by the reversal of solar elastosis with IMPES may alter the paracrine behavior fibroblasts. Reduction of the pro-melanogenesis paracrine factors in the lesional skin may potentially lead to decreased melanogenesis, thus lightening of melasma.

Although many therapies of various therapeutic efficacies exist today, the treatment of melasma has been challenging. In our patients with resistant melasma, the IMPES treatments were found to be an effective adjunctive treatment option, resulting in clinical improvement of melasma which was previously refractory to standard LFQSNY and TLA. Future studies should include histological evaluation to elucidate possible therapeutic mechanisms and long-term follow-up to monitor for recurrence.

\section{REFERENCES}

1. Kang WH, Yoon KH, Lee ES, Kim J, Lee KB, Yim H, et al. Melasma: histopathological characteristics in 56 Korean patients. Br J Dermatol 2002;146:228-37.

2. Hernández-Barrera R, Torres-Alvarez B, Castanedo-Cazares JP, Oros-Ovalle C, Moncada B. Solar elastosis and presence of mast cells as key features in the pathogenesis of melasma. Clin Exp Dermatol 2008;33:305-8.

3. Torres-Álvarez B, Mesa-Garza IG, Castanedo-Cázares JP, Fuentes-Ahumada C, Oros-Ovalle C, Navarrete-Solis J, et al. Histochemical and immunohistochemical study in melasma: evidence of damage in the basal membrane. Am J Dermatopathol 2011;33:291-5.

4. Kim EH, Kim YC, Lee ES, Kang HY. The vascular characteristics of melasma. J Dermatol Sci 2007;46:111-6.

5. Sheth VM, Pandya AG. Melasma: a comprehensive update: part II. J Am Acad Dermatol 2011;65:699-714.

6. Polnikorn N. Treatment of refractory dermal melasma with the MedLite C6 Q-switched Nd:YAG laser: two case reports. J Cosmet Laser Ther 2008;10:167-73.

7. Mun JY, Jeong SY, Kim JH, Han SS, Kim IH. A low fluence Q-switched Nd:YAG laser modifies the 3D structure of melanocyte and ultrastructure of melanosome by subcellularselective photothermolysis. J Electron Microsc (Tokyo) 2011;60: $11-8$.

8. Kauvar AN. The evolution of melasma therapy: targeting melanosomes using low-fluence $Q$-switched neodymiumdoped yttrium aluminium garnet lasers. Semin Cutan Med Surg 2012;31:126-32.
9. Goldberg DJ, Berlin AL, Phelps R. Histologic and ultrastructural analysis of melasma after fractional resurfacing. Lasers Surg Med 2008;40:134-8.

10. Hantash BM, Bedi VP, Sudireddy V, Struck SK, Herron GS, Chan KF. Laser-induced transepidermal elimination of dermal content by fractional photothermolysis. J Biomed Opt 2006;11: 041115.

11. Rokhsar CK, Fitzpatrick RE. The treatment of melasma with fractional photothermolysis: a pilot study. Dermatol Surg 2005; 31:1645-50.

12. Halachmi S, Haedersdal M, Lapidoth M. Melasma and laser treatment: an evidenced-based analysis. Lasers Med Sci 2014; 29:589-98.

13. Karsai S, Fischer T, Pohl L, Schmitt $L$, Buhck $H$, Jünger $M$, et al. Is non-ablative 1550-nm fractional photothermolysis an effective modality to treat melasma? Results from a prospective controlled single-blinded trial in 51 patients. J Eur Acad Dermatol Venereol 2012;26:470-6.

14. Lee HS, Won CH, Lee DH, An JS, Chang HW, Lee JH, et al. Treatment of melasma in Asian skin using a fractional 1,550-nm laser: an open clinical study. Dermatol Surg 2009;35:1499-504.

15. Choi JR, Won CH, Oh ES, An J, Chang SE. Does altered basement membrane of melasma lesion affect treatment outcome in Asian skin? Am J Dermatopathol 2013;35:137-8.

16. Kim HS, Kim EK, Jung KE, Park YM, Kim HO, Lee JY. A splitface comparison of low-fluence Q-switched Nd: YAG laser plus $1550 \mathrm{~nm}$ fractional photothermolysis vs. Q-switched Nd: YAG monotherapy for facial melasma in Asian skin. J Cosmet Laser Ther 2013;15:143-9.

17. Taheri A, Mansoori P, Sandoval LF, Feldman SR, Williford PM, Pearce D. Entrance and propagation pattern of high-frequency electrical currents in biological tissues as applied to fractional skin rejuvenation using penetrating electrodes. Skin Res Technol 2014;20:270-3.

18. Berardesca E, Maibach H. Racial differences in skin pathophysiology. J Am Acad Dermatol 1996;34:667-72.

19. Lim SD, Yeo UC, Kim IH, Choi CW, Kim WS. Surgical corner. Evaluation of the wound healing response after deep dermal heating by fractional micro-needle radiofrequency device. J Drugs Dermatol 2013;12:1044-9.

20. Beltraminelli H, Dietrich N, Hunziker T. Fractional transepidermal delivery: a histological analysis. Dermatology 2011; 223:321-4.

21. Budamakuntla $L$, Loganathan $E$, Suresh $D H$, Shanmugam $S$, Suryanarayan S, Dongare A, et al. A randomised, open-label, comparative study of tranexamic acid microinjections and tranexamic acid with microneedling in patients with melasma. J Cutan Aesthet Surg 2013;6:139-43.

22. Na JI, Choi SY, Yang SH, Choi HR, Kang HY, Park KC. Effect of tranexamic acid on melasma: a clinical trial with histological 
evaluation. J Eur Acad Dermatol Venereol 2013;27:1035-9.

23. Passeron T, Fontas E, Kang HY, Bahadoran P, Lacour JP, Ortonne JP. Melasma treatment with pulsed-dye laser and triple combination cream: a prospective, randomized, single- blind, split-face study. Arch Dermatol 2011;147:1106-8.

24. Hantash BM, Ubeid AA, Chang H, Kafi R, Renton B. Bipolar fractional radiofrequency treatment induces neoelastogenesis and neocollagenesis. Lasers Surg Med 2009;41:1-9. 